ARTICLE

https://doi.org/10.1038/s41467-019-10503-7

\title{
Single-site glycine-specific labeling of proteins
}

\author{
Landa Purushottam¹, Srinivasa Rao Adusumalli ${ }^{1}$, Usha Singh², V.B. Unnikrishnan ${ }^{1}$, Dattatraya Gautam Rawale ${ }^{1}$ \\ Mansi Gujrati ${ }^{2}$, Ram Kumar Mishra ${ }^{2} \&$ Vishal Rai id ${ }^{1}$
}

Labeling of native proteins invites interest from diverse segments of science. However, there remains the significant unmet challenge in precise labeling at a single site of a protein. Here, we report the site-specific labeling of natural or easy-to-engineer N-terminus Gly in proteins with remarkable efficiency and selectivity. The method generates a latent nucleophile from $\mathrm{N}$-terminus imine that reacts with an aldehyde to deliver an aminoalcohol under physiological conditions. It differentiates $\mathrm{N}$-Gly as a unique target amongst other proteinogenic amino acids. The method allows single-site labeling of proteins in isolated form and extends to lysed cells. It administers an orthogonal aldehyde group primed for late-stage tagging with an affinity tag, ${ }^{19} \mathrm{~F}$ NMR probe, and a fluorophore. A user-friendly protocol delivers analytically pure tagged proteins. The mild reaction conditions do not alter the structure and function of the protein. The cellular uptake of fluorophore-tagged insulin and its ability to activate the insulin-receptor mediated signaling remains unperturbed.

\footnotetext{
${ }^{1}$ Department of Chemistry, Indian Institute of Science Education and Research (IISER) Bhopal, Bhopal 462066, India. ${ }^{2}$ Department of Biological Sciences, Indian Institute of Science Education and Research (IISER) Bhopal, Bhopal 462066, India. Correspondence and requests for materials should be addressed to V.R. (email: vrai@iiserb.ac.in)
} 
S ingle-site labeling of proteins facilitates investigation of several biological processes through attachment of biophysical probes, imaging probes, and toxins. Such labeling emerges through pre-engineered protein equipped with unnatural amino acids $^{1}$, an amino acid sequence recognized by enzymes ${ }^{2}$, and single cysteine $e^{3,4}$ or a cysteine placed in a $\pi$-clamp ${ }^{5}$. The understanding of organic chemistry with proteins has nurtured the growth of bioconjugation. These biomolecules can be perceived as a macromolecular substrate with multiple nucleophilic functional groups $\left(\mathrm{Nu}_{\mathrm{P}}\right)$. The obvious route for bioconjugation would involve its reaction with an electrophile (Fig. 1a). For single-site labeling in such cases, a functional group has to compete with all the other nucleophilic residues (chemoselectivity) and its additional copies (site-selectivity). The chemoselective labeling of low-frequency residues $\left(\mathrm{Cys}^{6,7}, \mathrm{Tyr}^{8}\right.$, and $\left.\operatorname{Trp}^{9}\right)$ can address the latter to some extent. For other cases, the single-site labeling of side chain functionalities could be driven through ligand-protein interaction ${ }^{10}$, linchpin directed modification ${ }^{11}$ or targeting the $\varepsilon$-amine of most reactive Lys residue $\left(\mathrm{N}^{\varepsilon}-\mathrm{NH}_{2}\right)^{12-16}$. Alongside, the $\mathrm{N}$-terminus a-amine $\left(\mathrm{N}^{\alpha}-\mathrm{NH}_{2}\right)$ has established its place as a notable reactivity hotspot. In a remarkable example, the biomimetic transformation of N-terminus residue delivers a carbonyl group primed for subsequent orthogonal reactions ${ }^{17}$.

The kinetic labeling of $\mathrm{N}^{\alpha}-\mathrm{NH}_{2}$ can be achieved through its chemoselective modification with an electrophile as determined by a few groups including us (Fig. 1a) ${ }^{18-30}$. The alternate route involves a latent electrophile $\left(\mathrm{E}_{\mathrm{L}}\right)$ generated in the form of imine from $\mathrm{N}^{\alpha}-\mathrm{NH}_{2}$ and aldehyde (Fig. 1b). It gives us the opportunity to address the two challenges in two separate steps. If we can generate $\mathrm{E}_{\mathrm{L}}$ chemoselectively, the nucleophile is only required to address the site-selectivity. This approach delivers reductive alkylation in a chemoselective transformation (path a, Fig. 1b) ${ }^{31}$. However, the site-selectivity gets compromised very early in the reaction in the presence of competing imines. On the contrary, the nucleophilic attack of backbone amide to imine generated by $\mathrm{N}^{\alpha}-\mathrm{NH}_{2}$ and 2-pyridinecarboxaldehyde can render isolable imidazolidinone with high selectivity (path b, Fig. 1b) ${ }^{32}$. Unfortunately, none of these methodologies can distinguish one $\mathrm{N}$ terminus residue from the other. In this perspective, $\mathrm{N}$-terminal Cys containing proteins can render unique reactivity to form thiazolidine with an aldehyde or 2-cyanobenzothiazole (path c, Fig. 1b) ${ }^{33-35}$. However, it is a challenge to identify unique reactivity for other $\mathrm{N}$-terminus residues. In particular, selective targeting of $\mathrm{N}$-terminus Gly poses a prominent complexity as there is no side-chain residue to assist.

Here, we demonstrate that an aldehyde with appropriately designed hydrogen bond acceptor can result in the exclusive labeling of $\mathrm{N}$-terminus Gly residue. The remarkable selectivity of $\mathrm{C}-\mathrm{C}$ bond formation extends from an amino acid to structurally diverse proteins. Besides, the protocol operates conveniently in a mixture of proteins or cell lysate. The residue-specific installation of an orthogonal aldehyde group renders analytically pure tagged proteins in high yields through the late-stage single-site introduction of the desired probe.

\section{Results}

We hypothesized that a multi-step transformation could provide a roadmap to address the challenge of chemoselectivity and residue selectivity. The initial generation of the $\mathrm{E}_{\mathrm{L}}$ with capability to generate another reactive center (latent nucleophile, $\mathrm{Nu}_{\mathrm{L}}$, path d) could provide the platform. While the first step can address chemoselectivity, the latter can give us an opportunity to explore the residue specificity. Also, the $\mathrm{Nu}_{\mathrm{L}}$ generated with a protein will be required to display orthogonal reactivity in the presence of proteinogenic nucleophiles (Fig. 1c). At first, the challenge was to design an imine that can generate the $\mathrm{Nu}_{\mathrm{L}}$ under physiological conditions. We hypothesized that $\mathrm{H}$-bond acceptors in the imine group (Fig. 1b) could assist proton shuttling and stabilize the $\mathrm{Nu}_{\mathrm{L}}$. We anticipated that the intramolecular $\mathrm{H}$-bond acceptors might overcome the competing intermolecular interactions with protein and solvent. Subsequently, we can explore the reactivity of $\mathrm{Nu}_{\mathrm{L}}$ towards an external electrophile (Fig. 1c). Also, we anticipated that the unsubstituted amino acid (Gly) could potentially render a reactivity profile different from all the other substituted amino acids.

Aminoalcohol formation with Gly under ambient conditions. We selected ortho-substituted benzaldehyde to garner the advantage of geometrical constraint imposed by the aromatic ring. We placed one $\mathrm{H}$-bond acceptor ortho to the aldehyde in the form of a methoxy group (2a, Fig. 2a). The reaction of Gly amide $\mathbf{1 a}$ with reagent $\mathbf{2 a}$ fails to result in any adduct (Fig. 2a). Next, we designed the reagent $\mathbf{2} \mathbf{b}$ that proffers a carbonyl group as $\mathrm{H}$-bond acceptor. It was exciting to note the formation of isolable product (3ab, 27\% conversion, LC-MS). Encouraged by this result, we

a Selectivity landscape in labeling of ' $\mathrm{Nu}_{\mathrm{p}}$ ' in proteins

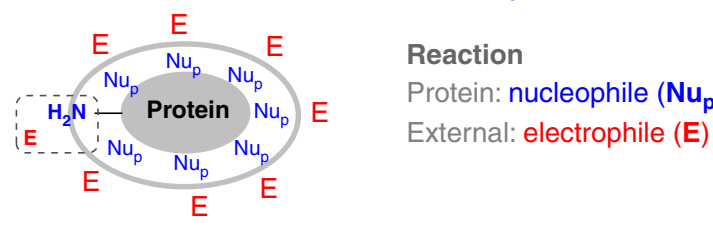

b $\mathrm{N}$-terminus labeling of proteins enabled by ' $\mathrm{E}_{\mathrm{L}}$ '

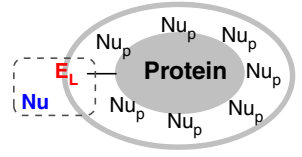

Reaction

Protein: latent electrophile $\left(\mathrm{E}_{\mathrm{L}}\right)$

External/internal: nucleophile (Nu)

C This work: ' $N u_{L}$ ' enables residue-specific labeling

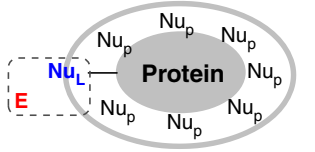

Reaction

Protein: latent nucleophile $\left(\mathrm{Nu}_{\mathrm{L}}\right)$

External: electrophile (E)

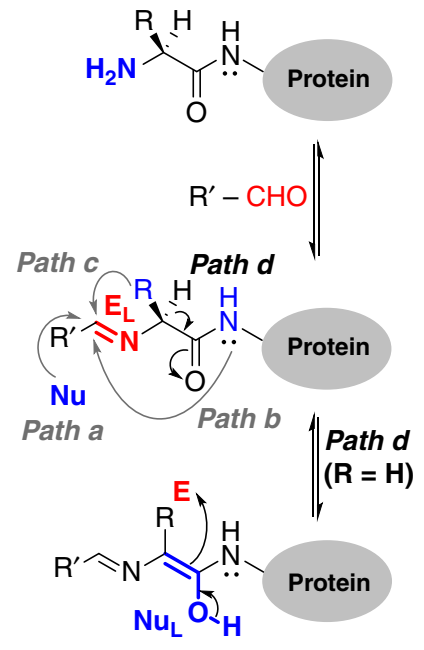

Fig. 1 Residue-specificity in labeling of proteins. a Nucleophilic addition of protein residues to an electrophile. b A latent electrophile, imine, renders the $\mathrm{N}$-terminus labeling of proteins (path a-path c). c Latent nucleophile enables single-site $\mathrm{N}$-terminus Gly labeling 
a<smiles>[R]c1ccccc1C=O</smiles>

$2(50 \mathrm{mM})$

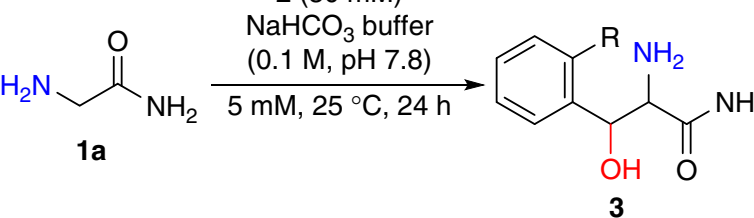<smiles>COc1ccccc1C=O</smiles>

b

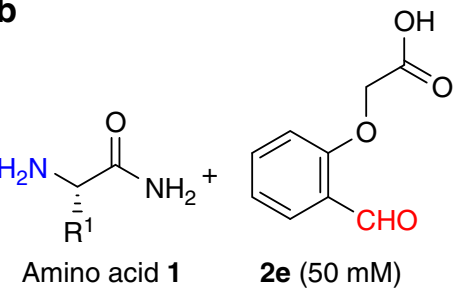

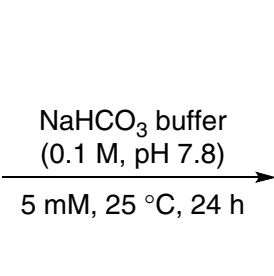<smiles>[R7]C(N)(C(N)=O)C(O)c1ccccc1OCC(=O)O</smiles>
$\mathrm{R}^{1}=\mathrm{H}(\mathbf{3 a})>95 \%$ $\mathrm{R}^{1} \neq \mathrm{H}(\mathbf{3 b}-3 \mathrm{t}) 0 \%$<smiles>[R7]C(N=Cc1ccccc1OCC(=O)O)C(N)=O</smiles>

Variable/reversible

Gly (1a), Ala (1b), Arg (1c), Asn (1d), Asp (1e)

Cys (1f), Glu (1g), Gln (1h), His (1i), Ilel (1j)

Leu (1k), Lys (1), Met (1m), Phe (1n), Prol (10)

$\operatorname{Ser}(\mathbf{1 p}), \operatorname{Thr}(\mathbf{1 q}), \operatorname{Trp}(\mathbf{1 r}), \operatorname{Thr}(\mathbf{1 s}), \operatorname{Val}(\mathbf{1 t})$

C<smiles>NC(=O)[C@H](N)Cc1ccccc1</smiles>

d

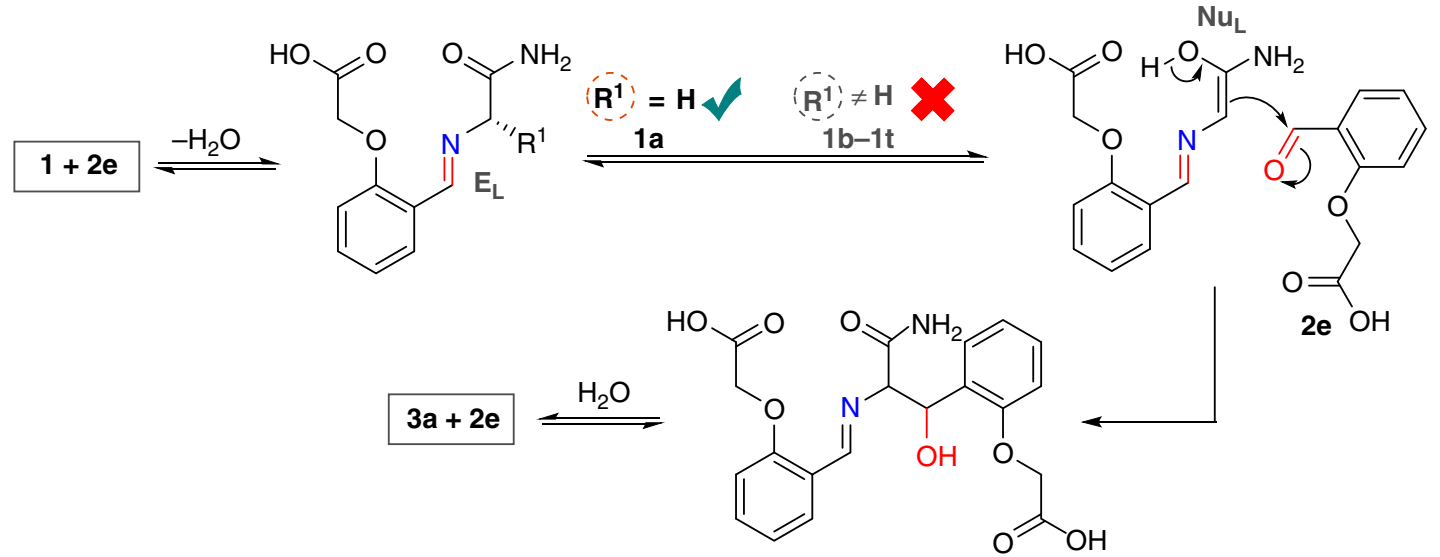

Fig. 2 Stable aminoalcohol formation with glycine. a Aldehyde with H-bond acceptors forms a stable aminoalcohol with 1a (also see Supplementary Fig. 72). b Selective formation of aminoalcohol with 1a. c Stereo-stability of substituted amino acid (1n) under the reaction conditions. d Plausible mechanism for glycine specific formation of aminoalcohol

investigated the effect of two oxygen centers as H-bond acceptors in the reagent $2 \mathrm{c}$. We found it to be inefficient in improving the conversion to the product (3ac, 33\%, LC-MS). The redesigned reagent $2 \mathrm{~d}$ led to $63 \%$ conversion of the product that further enhanced (3a, $>95 \%$, LC-MS) with reagent 2e. A non-polar derivative of product (3a) was purified and characterized as aminoalcohol after thorough mass and NMR analysis (Supplementary Figs. 13-27).

Unsubstituted amino acid versus substituted amino acids. In another exciting result, we noted that the imine formed by Ala $\mathbf{1 b}$ remained inert towards any subsequent transformation contrary to Gly 1a (Fig. 2b and Supplementary Table 2). With this data in hand, we examined whether all the other proteinogenic amino acids (1c-1t) behave similarly to Ala $\mathbf{1 b}$. No trace of product $3 \mathbf{b}-\mathbf{3 t}$ except imine formation $\mathbf{4 b}-\mathbf{4 t}$ was observed with the amino acids $\mathbf{1 b}-\mathbf{1 t}$ (Fig. $2 \mathrm{~b}$ and Supplementary Table 2). In a control experiment, the vortexing of Phe (1n) under the reaction conditions did not result in its racemization (Fig. $2 c$ and Supplementary Fig. 48). These results reconfirm the presence of a high barrier to the formation of the $\mathrm{Nu}_{\mathrm{L}}$ in substituted amino acids (1b-1t, Fig. $2 \mathrm{~d}$ ). We believe that the unfavorable orientation of the H-bond acceptor in these cases inhibit the process. Also, 
the imine from the Lys side chain $\left(\mathrm{N}^{\varepsilon}-\mathrm{NH}_{2}\right)$ remains unreactive for any subsequent transformation (see Supplementary Fig. 73).

N-terminus Gly labeling of large peptides and proteins. To explore the translation of aminoalcohol chemistry, we selected melittin 6a [26 residues, one $\mathrm{N}^{\alpha}-\mathrm{NH}_{2}$ (Gly), three Lys $\mathrm{N}^{\varepsilon}-\mathrm{NH}_{2}$ ]. The reaction of reagent $\mathbf{2 e}$ with $\mathbf{6 a}$ led to mono-labeled melittin 7a (52\% conversion, Fig. 3a); in a control experiment, RNase A $(\mathrm{N}$-terminus Lys) resulted in no detectable product in $72 \mathrm{~h}$. We confirmed the site of labeling (N-terminus Gly) by MS (labeled G1-Q26, $\mathrm{m} / z$ 3027.51 $[\mathrm{M}+\mathrm{H}]^{+}$) followed by MS-MS (Supplementary Fig. 49). Next, we selected a diagnostically relevant essential hemoprotein myoglobin $\mathbf{6 b}$ [153 residues, one $\mathrm{N}^{\alpha}-\mathrm{NH}_{2}$ (Gly), nineteen Lys $\mathrm{N}^{\varepsilon}-\mathrm{NH}_{2}$ ] and vortexed it with aldehyde $\mathbf{2 e}$. The mono-labeled myoglobin $(\mathbf{7 b}, 40 \%$ conversion) is formed exclusively in this case (Fig. 3a). Peptide mapping of the enzymatic digest (labeled G1-K16, $\mathrm{m} / z 1996.37$ $[\mathrm{M}+\mathrm{H}]^{+}$) and MS-MS confirmed the site of labeling at $\mathrm{N}$-terminus Gly (Supplementary Fig. 50). It was imperative to evaluate the chemistry with recombinant proteins. The engineering of Gly at the $\mathrm{N}$-terminus of proteins is convenient ${ }^{36}$. In bacteria, the N-terminal Met is excised from proteins exposing the penultimate Gly with high efficiency ${ }^{37}$. Also, the recombinant proteins expressed with a recognition sequence for prescission protease renders the desired N-terminus Gly post proteolytic digestion ${ }^{38}$. We adopted the latter route and generated small Ubiquitin-like modifier (SUMO1) protein $\mathbf{6 c}$ with a Gly residue at the N-terminus (see Supplementary information for details). The labeling of $\mathbf{6 c}$ with $2 \mathbf{e}$ went smoothly to result in N-terminus mono-labeled SUMO1 (7c, 43\% conversion, Fig. 3a). Peptide mapping (labeled G1-L3, $\mathrm{m} / z$ 466.37

a
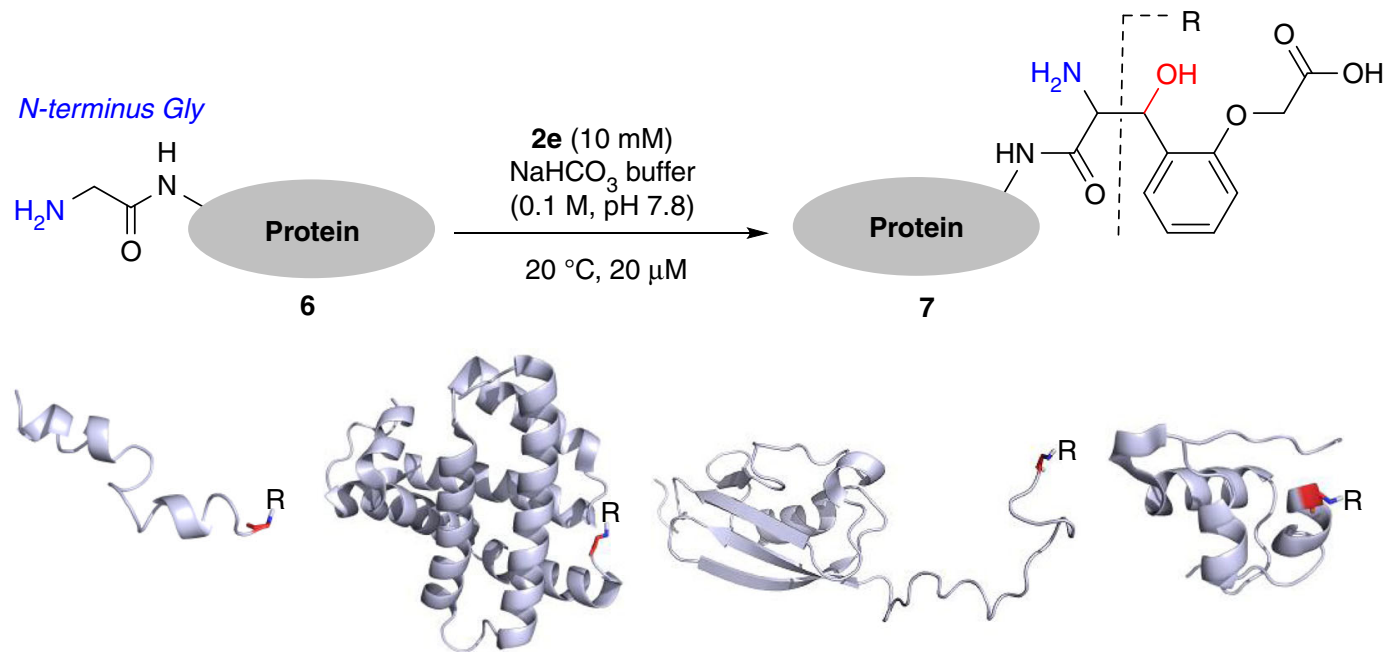

7a, $\mathbf{N}^{\alpha-R-M e l i t t i n ~(52 \%), ~} 48 \mathrm{~h} \quad$ 7b, $\mathbf{N}^{\alpha}-\mathrm{R}-$ Myoglobin (40\%), $48 \mathrm{~h}$
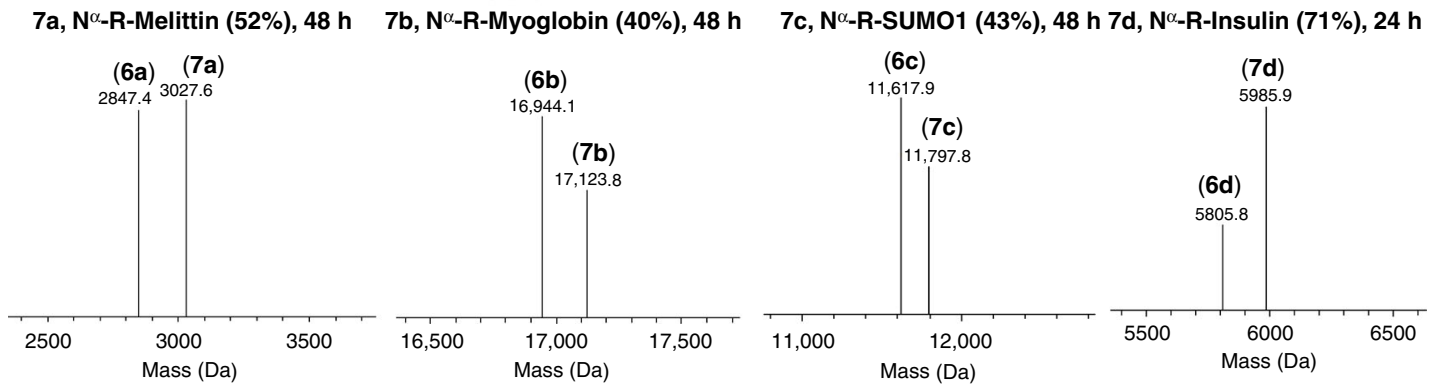

b

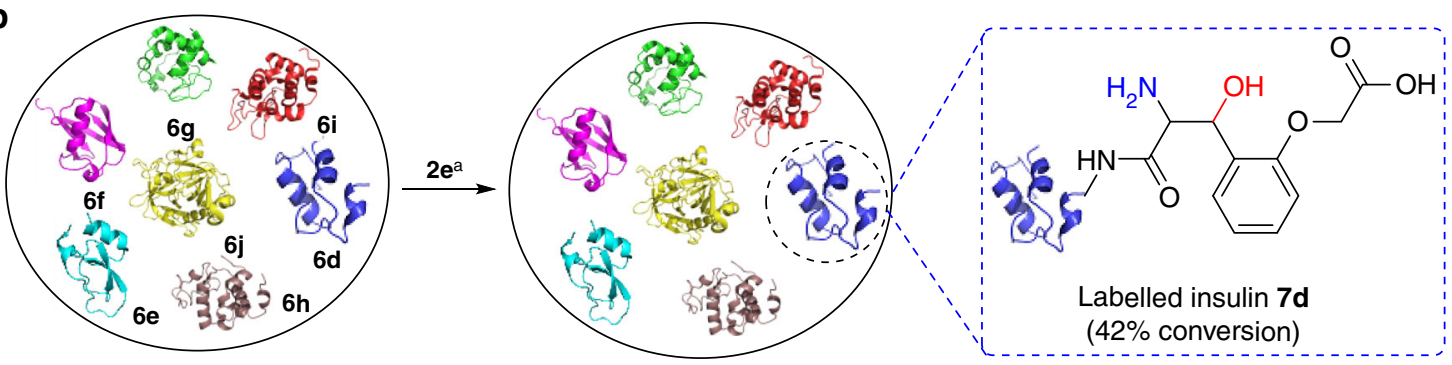

Proteins (N-terminus residue)

Insulin (Gly) 6d, Aprotinin (Arg) 6e, Ubiquitin (Met) 6f, Cytochrome C (Ac-Gly) 6g Lysozyme C (Lys) 6h, $\beta$-Lactoglobulin (Leu) 6i, Chymotrypsinogen A (Cys) 6j

${ }^{\mathrm{a}} \mathrm{NaHCO}_{3}$ buffer $(0.1 \mathrm{M}, \mathrm{pH} 7.8), 50 \mu \mathrm{M}, 48 \mathrm{~h}, 25^{\circ} \mathrm{C}$

Fig. $3 \mathrm{~N}$-terminus Gly labeling of proteins. a A user-friendly protocol delivers single-site labeling of proteins. Deconvoluted ESI-MS confirms the \% conversion and rules out the possibility of side reactions (also see Supplementary Figs. 70 and 71 ). $\mathbf{R}$ indicates the fragment from reagent $\mathbf{2 e}$ attached to the protein. $\mathbf{b}$ Extension of methodology for labeling single protein (insulin $\mathbf{6} \mathbf{d}$ ) in a mixture of proteins $(\mathbf{6} \mathbf{d}-\mathbf{6 j}$ ) 
$\left.[\mathrm{M}+\mathrm{H}]^{+}\right)$and MS-MS confirmed the site of labeling at $\mathrm{N}$ terminus Gly (Supplementary Fig. 51). Next, we selected insulin 6d that contains two $\mathrm{N}$-terminus [51 residues, two $\mathrm{N}^{\alpha}-\mathrm{NH}_{2}$, chain A (Gly), chain B (Phe), one Lys $\left.\mathrm{N}^{\varepsilon}-\mathrm{NH}_{2}\right]$. The imine formed by $\mathrm{N}^{\alpha}-\mathrm{NH}_{2}$ (Phe) of chain $\mathrm{B}$ is established to exhibit the preferential reactivity ${ }^{21-23}$. However, the vortexing of insulin $\mathbf{6 d}$ with the reagent $2 \mathbf{e}$ results in the mono-labeled insulin $\mathbf{7 d}$ in $71 \%$ conversion (Fig. 3a). The disulfide reduction of $\mathbf{7 d}$, peptide mapping, and MS-MS led to the identification of $\mathrm{N}^{\alpha}-\mathrm{NH}_{2}$ (Gly) modification in chain A (labeled G1-N21, $m / z 2563.00[\mathrm{M}+\mathrm{H}]$ + , Supplementary Fig. 52). Next, we selected a mixture of seven proteins (6d-6j, Fig. 3b). Gratifyingly, the labeling experiment with reagent $2 \mathrm{e}$ resulted in exclusive labeling of $\mathrm{N}$-terminus Gly bearing insulin $\mathbf{6 d}$ to render mono-labeled product $7 \mathbf{d}(42 \%$ conversion, Fig. 3b and Supplementary Fig. 53). The methodology exhibits remarkable selectivity as none of the other residues in any protein interfere.

Access to analytically pure tagged proteins. At this stage, understanding the impact of functional group derivatizations of $2 \mathrm{e}$ on the reaction was essential for achieving the downstream tasks. We found that the amide linkage could be used while redesigning the reagent $\mathbf{2 e}$ to a symmetric bis-aldehyde ( $\mathbf{2} \mathbf{f}$ and $\mathbf{2 g}$, Fig. 4a) with the handle for late-stage modification. Initially, the reaction of insulin with bis-aldehyde $2 \mathbf{f}$ resulted in poor conversions. However, the incorporation of polyethylene glycol $(\mathrm{PEG})_{3}$ linker in redesigned aldehyde $\mathbf{2} \mathbf{g}$ regained the solubility of reagent and efficiency of transformation $(88 \%$, step 1 , Fig. $4 \mathrm{~b}$; for the reaction of proteins $\mathbf{6 a}-\mathbf{6} \mathbf{c}$ and PfAOS1 $\mathbf{6 k}$ with $\mathbf{2 g}$, see Supplementary Figs. 62-64). We did not observe the formation of insulin-insulin complex (Supplementary Table 3 and Fig. 65). Initially, we examined the efficiency of late-stage installation with benzyloxyamine. The product characterization involved disulfide reduction, peptide mapping, and MS-MS (Supplementary Figs. 54 and 55). Subsequently, we showcased the potential of this transformation with derivatives of O-hydroxylamine such as ${ }^{19} \mathrm{~F}$ NMR probe 10a, biotin 10b, and a fluorophore 10c (step 2a, Fig. 4b). The excellent overall conversion $(85 \%, 87 \%$, and $87 \%$, respectively) over the two steps (steps 1 and $2 \mathrm{a}$; route 1) while retaining the selectivity is noteworthy (Supplementary Figs. 56-59). ${ }^{19}$ F NMR probe attached insulin 11a shows a sharp NMR signal at $-62.80 \mathrm{ppm}$ (Fig. 4 and Supplementary Fig. 66). The incubated mixture of biotinylated insulin $\mathbf{1 1 \mathbf { b }}$ and

a

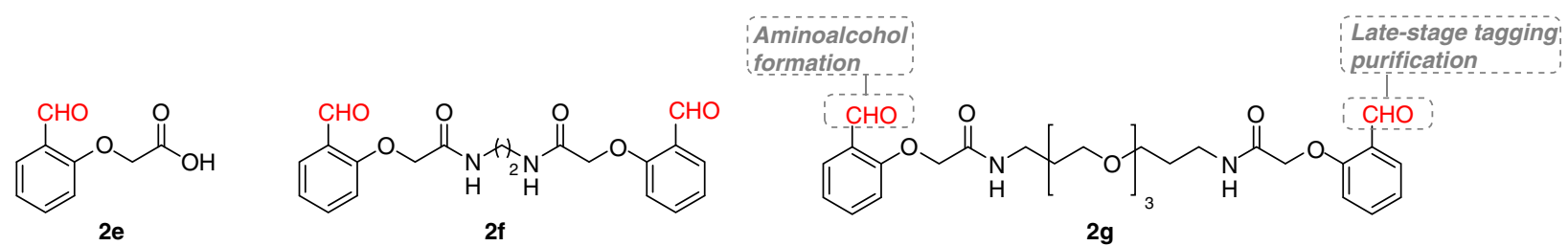

b

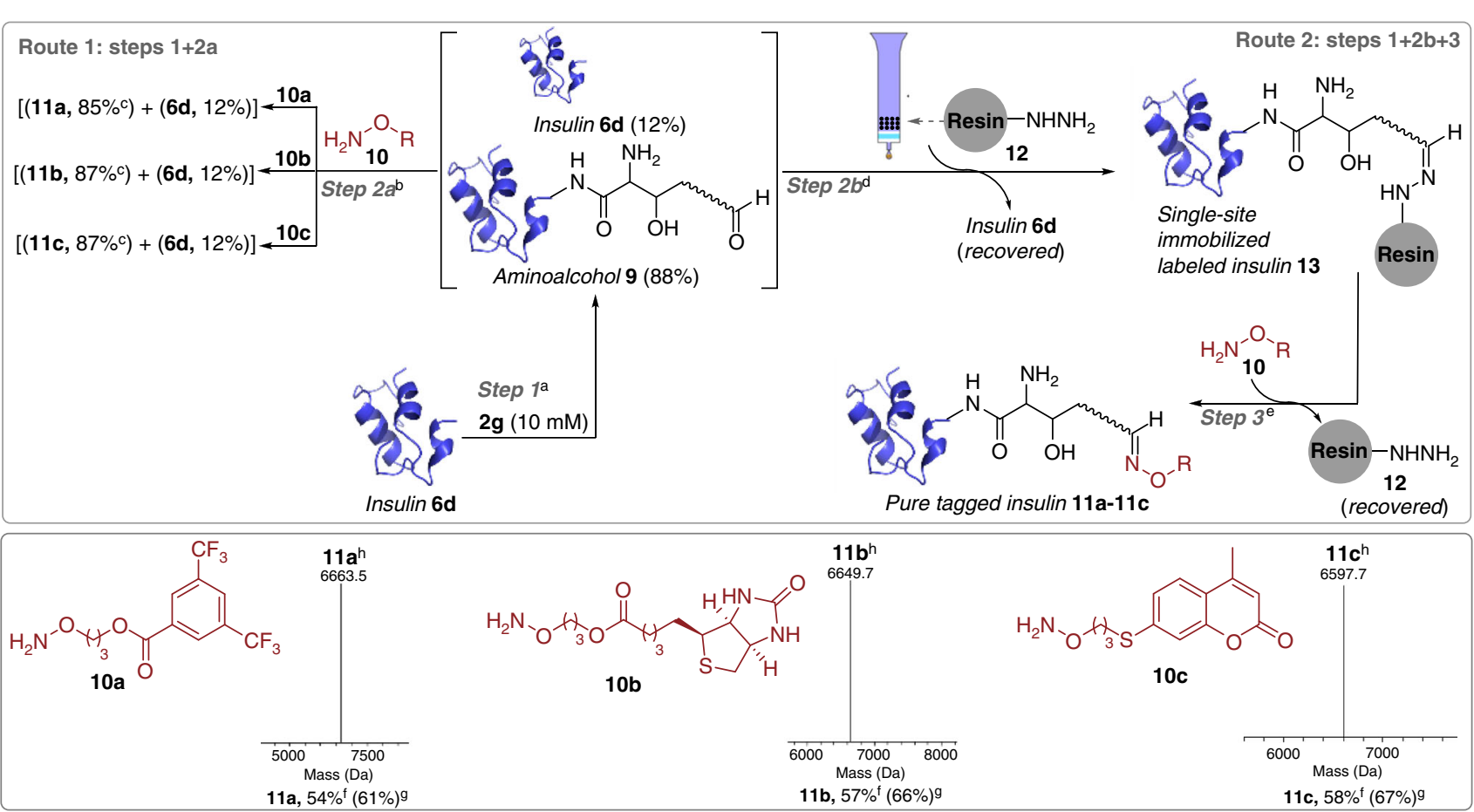

${ }^{a} \mathrm{NaHCO}_{3}$ buffer $(0.1 \mathrm{M}, \mathrm{pH} 7.8), 20 \mu \mathrm{M}, 24 \mathrm{~h}, 25^{\circ} \mathrm{C}$. ${ }^{\mathrm{b}} 3-5 \mathrm{~h}, 25^{\circ} \mathrm{C}$. c Overall \% conversion for two steps. ${ }^{\mathrm{d} A n i l i n e, ~ p h o s p h a t e ~ b u f f e r ~}(0.1 \mathrm{M}, \mathrm{pH}$ 7.0), $10 \mathrm{~h}$. eAniline. phosphate buffer $(0.3 \mathrm{M}, \mathrm{pH} 7.0), 8 \mathrm{~h}$. ${ }^{f}$ Overall \% isolated yield for three steps. $9 \%$ Yield is based on recovered starting material (brsm). hDeconvoluted ESI-MS spectrum for analytically pure tagged protein.

Fig. 4 Late-stage tagging and isolation of analytically pure tagged proteins. a Design elements of a symmetric bis-aldehyde. $\mathbf{b}$ Insulin is labeled through aminoalcohol formation with reagent $\mathbf{2} \mathbf{g}$. The labeled insulin $\mathbf{9}$ can be treated with derivatives of O-hydroxylamine $\mathbf{1 0 a}$ - $10 \mathbf{c}$ for tagging them with ${ }^{19} \mathrm{~F}-\mathrm{NMR}$ probe, biotin, and coumarin. Alternatively, it can be immobilized on hydrazide functionalized resin through single-site to deliver $\mathbf{1 3}$. The unreacted insulin $\mathbf{6 d}$ is recovered and recycled. Subsequent treatment of $\mathbf{1 3}$ with 10a delivers analytically pure 11a after removing excess 10a through spin concentration. The hydrazide functionalized resin $\mathbf{1 2}$ is recovered and recycled multiple (5-8) times without loss of activity. Similar protocol renders pure $\mathbf{1 1 b}$ and $\mathbf{1 1 c}$ For single-step late-stage installation of a probe, please see Supplementary Fig. 74 
streptavidin (Stv-n) renders a sharp band at $\sim 70 \mathrm{kDa}$ for Stv-11b complex (Supplementary Fig. 67). The coumarin attached insulin $11 \mathrm{c}$ results in fluorescence emission at $428 \mathrm{~nm}$ (excitation at 333 nm, Supplementary Fig. 68).

Our next goal was to integrate a purification protocol with the aminoalcohol chemistry (steps $1,2 \mathrm{~b}$, and 3; route 2; Fig. 4b). Initially, we mixed the reaction mixture of step $1(\mathbf{9}+\mathbf{6 d})$ with hydrazide functionalized resin (step 2b, Fig. 4b). This step exhibits excellent efficiency and results in $>95 \%$ single-site immobilization of the labeled protein (9). The unreacted protein (6d) was recovered with $>95 \%$ efficiency and recycled. Finally, the immobilized protein (13) was released with O-hydroxylamine derivatives $(\mathbf{1 0 a}-\mathbf{1 0 c})$ from resin through transoximization (step 3 , Fig. 4b). The centrifugal spin concentration results in the analytically pure single-site tagged protein (Supplementary Figs. 60 and 61). The single-site immobilized labeled insulin rendered efficient parallel installation of ${ }^{19} \mathrm{~F}$ NMR probe, biotin, and fluorophore (three steps, two purifications; 54\%, 57\%, and $58 \%$ overall isolated yields; Supplementary Figs. 60 and 61 ). The coumarin tagged insulin (11c) exhibits excellent product stability over a broad range of $\mathrm{pH}(3-11)$ at $25^{\circ} \mathrm{C}$ for $36 \mathrm{~h}$ (Supplementary Fig. 76).

Bioactivity assays. Subsequently, we asked how the labeling would affect the structure and activity of insulin. The earlier investigations suggest that $\mathrm{N}^{\alpha}-\mathrm{NH}_{2}$ (Gly) of chain A is important for insulin structure and function ${ }^{39,40}$. The circular dichroism of coumarin tagged insulin (11c) confirmed the conservation of structure (Supplementary Fig. 69). We examined the activity in cell-based assays using 11c through its ability to activate insulin receptor (IR) mediated signaling. Activation of insulin-dependent IR-signaling was assessed by the increase in levels of phospho-Akt (pSer-473) and subsequent uptake of insulin inside the cells. The prior is detected by phospho-Akt (pAkt) specific antibodies on western blotting and immunofluorescence. The latter is assessed through the coumarin fluorophore signal inside cells. While the untreated (mock) cells exhibit basal pAkt reactivity, cells treated with 11c or untagged insulin (6d) render enhanced phospho-Akt (pAkt) reactivity relative to loading control protein (GAPDH) (Supplementary Fig. 78a). The quantitation of pAkt signals relative to loading control GAPDH is represented in Supplementary Fig. $78 \mathrm{~b}$. These observations directed us towards the estimation of EC50 values for native and modified insulin ${ }^{41}$. Both native and modified insulin activated the insulin receptor and pAkt generation with similar efficacy (Fig. 5a). The EC50 values were estimated to be 2.7 and $2.9 \mathrm{nM}$ for native (6d) and modified insulin (S29), respectively (Fig. 5b). In the cellular uptake assays, we observed that cells treated with 11c display coumarin signal accumulated throughout the cells indicating their regular uptake (Fig. 5c, 1st row, middle panel). This signal can be competed out in the presence of excess untagged insulin (11c:6d, 1:3; Fig. 5c, 1st row, right panel). Concomitant to this, we observe a similar increase in pAkt signals (pSer-473) in tagged or untagged insulintreated cells (Fig. 5d, $1^{\text {st }}$ row middle and right panels). These observations unambiguously establish that aminoalcohol derivatization of N-Gly in insulin results in no adverse effect on its capability to activate the insulin receptor signaling. Next, we investigated the SUMOylation reaction that provides a versatile tool to identify and characterize novel SUMO enzymes and their substrates ${ }^{42}$. We reconstituted the SUMOylation reaction with modified SUMO1 and monitored the SUMO1-substrate conjugate. The data concludes that the N-Gly modification of SUMO1 does not interfere with its biochemical activity (for details, see Supplementary Fig. 79).

Residue-specific labeling of a protein in cell lysate. Finally, we challenged the methodology to precisely label the N-terminus Gly containing protein in a cell lysate prepared from E. coli BL21 (DE3) cells overexpressing GST-SUMO1. Proteolytic digest generates N-terminal Gly containing SUMO1 in a mixture of a

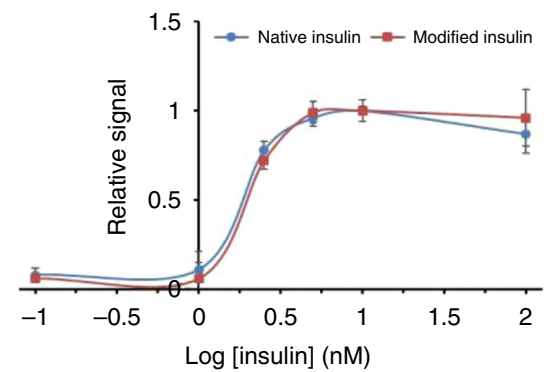

C

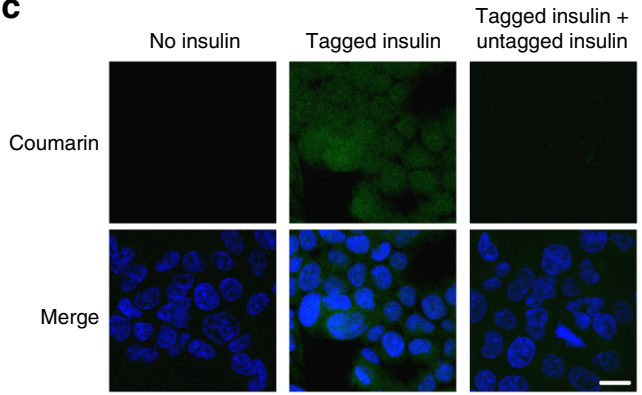

b

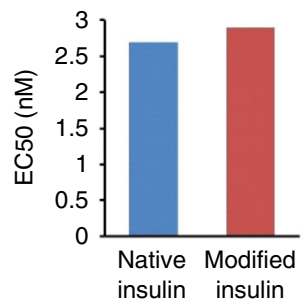

d

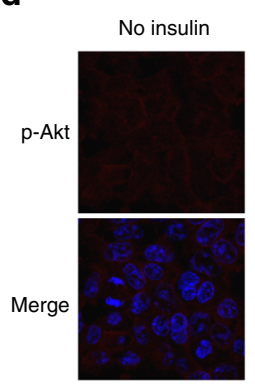

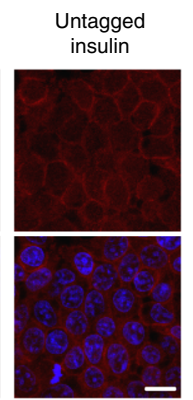

Fig. 5 Insulin bioactivity assay. a, Bioactivity measurement for native and modified insulin in a dose-dependent pAkt cell-based assay. The error bar represents standard error of mean (SEM). The assays were repeated at least three times $(n=3)$. b EC50 value determination from (a), absolute values obtained by extrapolation of graphs in a are represented by a simple bar graph. c Uptake of tagged insulin (green) and mixture of untagged and tagged insulin in cells. Chromatin (blue). Also see, Supplementary Fig. 77. d Activation of IR signaling and pAkt (red) accumulation in HEK293T cells after insulin treatment (scale bar:10 $\mu \mathrm{m}$ ). Source data of Fig. 5 panel a provided as Source Data file 
a

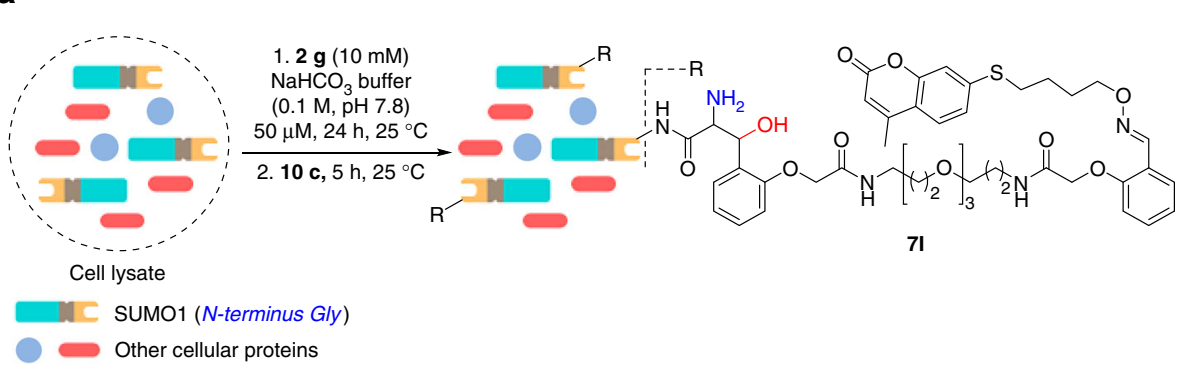

b

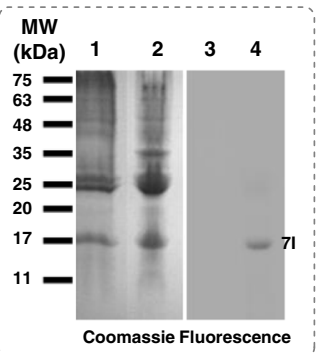

Fig. 6 Residue-specific labeling of a protein in the cell lysate. a Selective labeling of N-Gly SUMO1 with coumarin tag in cell lysate. b 12\% SDS-PAGE of cell lysate (overexpressed with SUMO1) and coumarin-tagged SUMO1 $\mathbf{7 l}$ in cell lysate followed by coomassie staining and fluorescence imaging. MW-molecular weight, Lanes 1 and 2: cell lysate before and after reaction (Coomassie); lanes 3 and 4: cell lysate before and after reaction (fluorescence). The band at $\sim 17 \mathrm{kDa}(\mathrm{m} / \mathrm{z} 11.6 \mathrm{kDa})$ in lanes corresponds to the SUMO1. The band at $\sim 17 \mathrm{kDa}(\mathrm{m} / \mathrm{z} 11.6 \mathrm{kDa})$ shown by fluorescence imaging in lane 4 confirms the selective tagging of SUMO1 (7I). Source data of Fig. 6 panel $\mathbf{b}$ provided as Source Data file

multiple other proteins present in the lysate sample (lanes 1 and 2, Fig. 6). Such a lysate was vortexed with the symmetrical bisaldehyde $\mathbf{2 g}$. The late-stage installation of coumarin on the $\mathrm{N}$-terminal Gly residue is visualized by SDS-PAGE and fluorescence imaging. The labeling of SUMO1 is observed without noticeable participation of any other protein (lane 4, Fig. 6).

\section{Discussion}

In summary, we deliver a methodology that enables single-site residue-specific labeling of a protein. We demonstrated that a systematic multi-step approach could provide the platform to solve the multifaceted selectivity challenges. The chemoselective generation of an electrophilic intermediate followed by site- and residue-specific formation of a latent nucleophile is the key to success. The reaction proceeds exclusively with the N-terminus Gly residue of a protein. The selectivity remains uncompromised even when the method is extended to a protein in the cell lysate. The reaction excludes the $\mathrm{N}$-terminus $a$-amine of other proteinogenic amino acids and multiple Lys residues bearing $\varepsilon$-amine. The absence of competing reactions is one of the most noteworthy features of this chemical technology. The symmetric bisaldehyde reagent allows installation of various tags on single-site labeled protein. A user-friendly purification protocol enables the isolation of analytically pure tagged protein. The overall yield of the product after three steps is remarkable. The protocol offers convenient imaging of insulin in HEK293T cells without perturbing its structure and activity.

\section{Methods}

Single-site labeling of a protein. In a $1.5 \mathrm{~mL}$ microcentrifuge tube, protein ( $3 \mathrm{nmol}$ ) was mixed with sodium bicarbonate buffer $(120 \mu \mathrm{l}, 0.1 \mathrm{M}, \mathrm{pH} 7.8)$. To this solution, 2-(2-formylphenoxy) acetic acid 2e (1500 nmol) in DMSO (30 $\mu \mathrm{l})$ from a freshly prepared stock solution was added and vortexed at $25^{\circ} \mathrm{C}$. The overall concentration of protein and 2-(2-formylphenoxy)acetic acid was $20 \mu \mathrm{M}$ and 10 $\mathrm{mM}$ respectively. After $24-48 \mathrm{~h}$, the reaction mixture was diluted with acetonitrile: water $(10: 90,3000 \mu \mathrm{l})$. Unreacted 2-(2-formylphenoxy)acetic acid and salts were removed by using Amicon ${ }^{\circledR}$ Ultra- $0.5 \mathrm{~mL} 3-\mathrm{kDa}$ or $10-\mathrm{kDa}$ MWCO centrifugal spin concentrator. The protein mixture was further washed with Millipore Grade I water $(5 \times 0.4 \mathrm{~mL})$. The sample was analyzed by ESI-MS or MALDI-ToF-MS. The aqueous sample was concentrated by lyophilization before subjecting it to digestion, peptide mapping, and sequencing by MS-MS.

Late-stage tagging and purification of a protein. Hydrazide beads $(200 \mu \mathrm{l}$, hydrazide resin loading: $16 \mu \mathrm{mol} \mathrm{mL}^{-1}$ ) were taken in a $5 \mathrm{~mL}$ fritted polypropylene chromatography column with end tip closures. Phosphate buffer $(0.1 \mathrm{M}, \mathrm{pH} 7.0$, $5 \times 1 \mathrm{~mL}$ ) was used to wash the beads. The beads were re-suspended in phosphate buffer $(100 \mu \mathrm{l}, 0.1 \mathrm{M}, \mathrm{pH} 7.0)$. Protein mixture $(250 \mu \mathrm{M})$ in phosphate buffer $(150$ $\mu \mathrm{l}, 0.1 \mathrm{M}, \mathrm{pH} 7.0)$ and aniline $(100 \mathrm{mM})$ in phosphate buffer $(100 \mu \mathrm{l}, 0.1 \mathrm{M}, \mathrm{pH} 7.0)$ were added to the beads followed by end-to-end rotation $(30 \mathrm{rpm}$, rotary mixer) at $25^{\circ} \mathrm{C}$. The progress of the immobilization of the labeled protein on hydrazide resin was monitored by UV-absorbance of the supernatant. After 8-10 h, the supernatant was collected and the beads were washed with phosphate buffer $(0.3 \mathrm{M}, \mathrm{pH}$
$7.3,4 \times 1 \mathrm{~mL})$ and $\mathrm{KCl}(1 \mathrm{M}, 3 \times 1 \mathrm{~mL})$ to remove the adsorbed protein from resin The beads were further washed with the phosphate buffer $(0.3 \mathrm{M}, \mathrm{pH} 7.0,4 \times 1 \mathrm{~mL})$ and re-suspended (phosphate buffer, $200 \mu \mathrm{l}, 0.3 \mathrm{M}, \mathrm{pH}$ 7.0). To release the labeled protein from its immobilized derivative, aniline $(100 \mathrm{mM})$ in phosphate buffer $(100 \mu \mathrm{l}, 0.3 \mathrm{M}, \mathrm{pH} 7.0)$ and coumarin or fluoro or biotin derivatives (only one at a time) of O-hydroxylamine $(50 \mu \mathrm{l}, 150 \mathrm{mM}$ in DMSO) were added followed by vortex at $25^{\circ} \mathrm{C}$ for $6-8 \mathrm{~h}$. The supernatant was collected while the salts, aniline, and $\mathrm{O}$-hydroxylamine were removed using the spin concentrator ( $3 \mathrm{kDa} \mathrm{MWCO})$. The purity of the labeled protein was confirmed by ESI-MS. The purification protocol renders analytically pure tagged protein.

Residue-specific labeling of a protein in cell lysate. The cell lysate was prepared from E. coli BL21 (DE3) cells overexpressing GST-SUMO1 (section 2d in Supplementary information). Protein concentration was determined by BCA assay and adjusted to $1.0 \mathrm{mg} \mathrm{mL}^{-1}$. Protein $(10 \mathrm{nmol})$ in sodium bicarbonate buffer $(120 \mu \mathrm{l}$, $0.1 \mathrm{M}, \mathrm{pH} 7.8)$ was taken in a $1.5 \mathrm{~mL}$ microcentrifuge tube. To this solution, $\mathrm{N}, \mathrm{N}$ (((oxybis(ethane-2,1-diyl))bis(oxy))bis(propane-3,1-diyl))bis(2-(2-formylphenoxy) acetamide) $2 \mathrm{~g}(5000 \mathrm{nmol})$ in DMSO $(30 \mu \mathrm{l})$ from a freshly prepared stock solution was added and vortexed at $25^{\circ} \mathrm{C}$. After $24 \mathrm{~h}$, the reaction mixture was diluted with acetonitrile:buffer $(10: 90,1500 \mu \mathrm{l})$. Unreacted N,N'-(( oxybis(ethane2,1-diyl))bis(oxy))bis(propane-3,1-diyl))bis(2-(2-formylphenoxy)acetamide) $\mathbf{2 g}$ and salts were removed by spin concentrator $(0.5 \mathrm{~mL} 3-\mathrm{kDa}$ MWCO). The solution was further washed with sodium bicarbonate buffer $(0.1 \mathrm{M}, \mathrm{pH} 7.8)$ and concentrated to $160 \mu$ l. To the concentrated sample in sodium bicarbonate buffer, derivatives of O-hydroxylamine 7-((3-(aminooxy)propyl)thio)-4-methyl-2H-chromen-2-one $(2 \mu \mathrm{mol}) \mathbf{1 0 c}$ in DMSO $(40 \mu \mathrm{l})$ from a freshly prepared stock solution was added to convert mono-labeled protein to its oxime derivative for 3-6 h. The excess of $\mathrm{O}$-alkoxyamine and salts were removed by the spin concentrator. The sample was analyzed by SDS-PAGE.

Biological assays. Imaging assays: The HEK293T (Cell Repository, NCCS, Pune India) cells were grown in a six-well plate with coverslips in Dulbecco's modified Eagle's medium (DMEM) containing $1 \%$ serum for $24 \mathrm{~h}$. Subsequently, the cells were washed twice with PBS and treated with coumarin tagged $11 \mathrm{c}$ and untagged insulin $6 \mathrm{~d}\left(3 \mu \mathrm{g} \mathrm{mL}^{-1}, 0.5 \mu \mathrm{M}\right)$ for $30 \mathrm{~min}$ in $10 \%$ FBS containing DMEM media. For competition experiment, tagged and untagged insulin were used in 1:3 ratios in final $2.0 \mu \mathrm{M}$ insulin concentration. Post-treatment, cells were again washed twice with PBS and fixed using $100 \%$ chilled methanol for $15 \mathrm{~min}$ at $-20^{\circ} \mathrm{C}$. The cells were then rehydrated and permeabilized with rehydration buffer $(10 \mathrm{mM}$ Tris, 150 $\mathrm{mM} \mathrm{NaCl}, 0.1 \%$ TritonX-100) for $10 \mathrm{~min}$. For coumarin tagged insulin imaging, nuclei were stained with Hoechst 33342 (Invitrogen) directly after permeabilization and images were taken. For pAkt imaging, cells were blocked with 5\% Normal Goat Serum (NGS) for $30 \mathrm{~min}$ at room temperature after rehydration. The cells were stained overnight with pAkt antibodies (1:200, Cell Signaling Technology) at $4{ }^{\circ} \mathrm{C}$ After primary antibody incubation, cells were washed three times with PBS-T (5 min each). Alexa Fluor-568 conjugated goat anti-rabbit IgG (1:800, Life Technologies) secondary antibody was used against pAkt. After this, the nuclei were stained with Hoechst 33342 (Invitrogen), and fluorescence images were captured on APOTOME/Zeiss LSM 780 confocal microscope. All image analysis was performed using ZEN (Zeiss) or Image J software.

EC50 analysis. For the assay, 50,000 human embryonic kidney cells (HEK293T) were grown in each well of a 96 - well plate to $\sim 50 \%$ confluence in DMEM supplemented with $10 \%$ fetal bovine serum (FBS) and antibiotics in a humidified incubator with $5 \% \mathrm{CO}_{2}$ at $37^{\circ} \mathrm{C}$. The cells were serum starved for $12 \mathrm{~h}$ in no serum DMEM media and then treated with varying concentrations $(100,10,5,2.5,1,0.5$, $0.1 \mathrm{nM}$ ) of insulin and modified insulin in no serum DMEM media for $40 \mathrm{~min}$ at $37^{\circ} \mathrm{C}$. After the treatment, the insulin-containing media was removed, cells were 
washed and intracellular level of pAkt Ser473 was measured using HTRF pAkt Ser473 kit (Cisbio, France, Catalogue No. 64AKSPET and Perkin Elmer, Catalogue No. TRF4002C) following the manufacturer's protocol. In brief, cells were lysed in $50 \mu \mathrm{l}$ of supplemented lysis buffer under mild horizontal shaking at room temperature for $45 \mathrm{~min}$. The homogenized cell lysate $(16 \mu \mathrm{l})$ was added to $4 \mu \mathrm{l}$ of the premixed antibody solutions in the HTRF 96-well detection plate. After $4 \mathrm{~h}$ of incubation at room temperature, the absorbance was recorded in a Cytation 5 multi-mode reader (BioTek Instrument, USA).

Reporting summary. Further information on research design is available in the Nature Research Reporting Summary linked to this article.

\section{Data availability}

All data supporting the findings of this study are available within the Article and its accompanying Supplementary Information file. The source data underlying Figs. 5a, $6 \mathrm{~b}$ and Supplementary Figures 63b, 67, 68, 69, 72, 78a, 79c is provided in the Source Data file. Raw data for all the NMR spectra and HPLC-MS/ESI-MS/MALDI-ToF-MS can be accessed from the corresponding author upon reasonable request.

Received: 7 September 2018 Accepted: 16 May 2019

Published online: 10 June 2019

\section{References}

1. Krall, N., da Cruz, F. P., Boutureira, O. \& Bernardes, G. J. L. Site-selective protein-modification chemistry for basic biology and drug development. Nat. Chem. 8, 103-113 (2016).

2. Rashidian, M., Dozier, J. K. \& Distefano, M. D. Enzymatic labeling of proteins: techniques and approaches. Bioconjugate Chem. 24, 1277-1294 (2013).

3. Shinmi, D. et al. One-step conjugation method for site-specific antibody-drug conjugates through reactive cysteine-engineered antibodies. Bioconjugate Chem. 27, 1324-1331 (2016).

4. Bernardim, B. et al. Stoichiometric and irreversible cysteine-selective protein modification using carbonylacrylic reagents. Nat. Commun. 7, 13128 (2016).

5. Zhang, C. et al. $\pi$-Clamp-mediated cysteine conjugation. Nat. Chem. 8 , 120-128 (2016).

6. Mantovani, G. et al. Design and synthesis of $\mathrm{N}$-maleimido-functionalized hydrophilic polymers via copper-mediated living radical polymerization: a suitable alternative to PEGylation chemistry. J. Am. Chem. Soc. 127, 2966-2973 (2005).

7. Backus, M. K. et al. Proteome-wide covalent ligand discovery in native biological systems. Nature 534, 570-574 (2016).

8. Joshi, N. S., Whitaker, L. R. \& Francis, M. B. A three-component Mannichtype reaction for selective tyrosine bioconjugation. J. Am. Chem. Soc. 126 15942-15943 (2004)

9. Antos, J. M. \& Francis, M. B. Selective tryptophan modification with rhodium carbenoids in aqueous solution. J. Am. Chem. Soc. 126, 10256-10257 (2004).

10. Chen, G. et al. Reactivity of functional groups on the protein surface: development of epoxide probes for protein labeling. J. Am. Chem. Soc. 125, 8130-8133 (2003).

11. Adusumalli, S. R. et al. Single-site labeling of native proteins enabled by a chemoselective and site-selective chemical technology. J. Am. Chem. Soc. 140, 15114-15123 (2018)

12. Purushottam, L., Adusumalli, S. R., Chilamari, M. \& Rai, V. Chemoselective and site-selective peptide and native protein modification enabled by aldehyde auto-oxidation. Chem. Commun. 53, 959-962 (2017).

13. Hacker, M. S. et al. Global profiling of lysine reactivity and ligandability in the human proteome. Nat. Chem. 9, 1181-1190 (2017).

14. Chilamari, M., Purushottam, L. \& Rai, V. Site-selective labeling of native proteins by a multicomponent approach. Chem. Eur. J. 23, 3819-3823 (2017).

15. Chilamari, M., Kalra, N., Shukla, S. \& Rai, V. Single-site labeling of lysine in proteins through a metal-free multicomponent approach. Chem. Commun. 54, 7302-7305 (2018)

16. Matos, M. J. et al. Chemo- and regioselective lysine modification on native proteins. J. Am. Chem. Soc. 140, 4004-4017 (2018).

17. Gilmore, J. M., Scheck, R. A., Esser-Kahn, A. P., Joshi, N. S. \& Francis, M. B. $\mathrm{N}$-terminal protein modification through a biomimetic transamination reaction. Angew. Chem. Int. Ed. 45, 5307-5311 (2006).

18. Singudas, R., Adusumalli, S. R., Joshi, P. N. \& Rai, V. A phthalimidation protocol that follows protein defined parameters. Chem. Commun. 51, 473-476 (2015).

19. Chen, X., Muthoosamy, K., Pfisterer, A., Neumann, B. \& Weil, T. Site-selective lysine modification of native proteins and peptides via kinetically controlled labeling. Bioconjugate Chem. 23, 500-508 (2012).
20. Chan, A. O. et al. Modification of $\mathrm{N}$-terminal $\alpha$-amino groups of peptides and proteins using ketenes. J. Am. Chem. Soc. 134, 2589-2598 (2012).

21. O' Harte, F. P. M. et al. Structure, antihyperglycemic activity and cellular actions of a novel diglycated human insulin. Peptides 21, 1519-1526 (2000).

22. O' Harte, F. P. M., Højrup, P., Barne, C. R. \& Flatt, P. R. Identification of the site of glycation of human insulin. Peptides 17, 1323-1330 (1996).

23. Mei, H., Yu, C. \& Chan, K. K. NB1-C16-Insulin: site-specific. Synth., Purif. Biol. Act. Pharm. Res 16, 1680-1686 (1999).

24. Busch, G. K. et al. Specific N-terminal protein labelling: use of FMDV 3Cpro protease and native chemical ligation. Chem. Commun. 3369-3371 (2008).

25. Geoghegan, K. F. \& Stroh, J. G. Site-directed conjugation of nonpeptide groups to peptides and proteins via periodate oxidation of a 2-amino alcohol. Application to modification at N-terminal serine. Bioconjugate Chem. 3, 138-146 (1992).

26. Bandyopadhyay, A., Cambray, S. \& Gao, J. Fast and selective labeling of $\mathrm{N}$-terminal cysteines at neutral $\mathrm{pH}$ via thiazolidino boronate formation. Chem. Sci. 7, 4589-4593 (2016).

27. Wagner, A. M. et al. N-terminal protein modification using simple aminoacyl transferase substrates. J. Am. Chem. Soc. 133, 15139-15147 (2011).

28. Williamson, D. J., Fascione, M. A., Webb, M. E. \& Turnbull, W. B. Efficient Nterminal labeling of proteins by use of sortase. Angew. Chem. Int. Ed. 51, 9377-9380 (2012).

29. Raj, M., Wu, H., Blosser, S. L., Vittoria, M. A. \& Arora, P. S. Aldehyde capture ligation for synthesis of native peptide bonds. J. Am. Chem. Soc. 137, 6932-6940 (2015).

30. Spears, R. J. \& Fascione, M. A. Site-selective incorporation and ligation of protein aldehydes. Org. Biomol. Chem. 14, 7622-7638 (2016).

31. Chen, D., Disotuar, M. M., Xiong, X., Wang, Y. \& Chou, D. H. Selective Nterminal functionalization of native peptides and proteins. Chem. Sci. 8, 2717-2722 (2017)

32. MacDonald, J. I., Munch, H. K., Moore, T. \& Francis, M. B. One-step sitespecific modification of native proteins with 2-pyridinecarboxyaldehydes. Nat. Chem. Biol. 11, 326-331 (2015).

33. Casi, G., Huguenin-Dezot, N., Zuberbühler, K., Scheuermann, J. \& Neri, D. Site-specific traceless coupling of potent cytotoxic drugs to recombinant antibodies for pharmacodelivery. J. Am. Chem. Soc. 134, 5887-55892 (2012).

34. Bandyopadhyay, A., Cambray, S. \& Gao, J. Fast and selective labeling of Nterminal cysteines via boronic acid-accelerated conjugation. Chem. Sci. 7, 4589-4593 (2016).

35. Ren, $\mathrm{H}$. et al. A biocompatible condensation reaction for the labeling of terminal cysteine residues on proteins. Angew. Chem. Int. Ed. 48, 9658-9662 (2009).

36. Waugh, D. S. An overview of enzymatic reagents for the removal of affinity tags. Protein Expr. Purif. 80, 283-293 (2011).

37. Hirel, P. H., Schmitter, J. M., Dessen, P., Fayat, G. \& Blanquet, S. Extent of Nterminal methionine excision from Escherichia coli proteins is governed by the side-chain length of the penultimate amino acid. Proc. Natl Acad. Sci. USA $\mathbf{8 6}$ 8247-8251 (1989).

38. Cordingley, M. G., Callahan, P. L., Sardana, V. V., Garsky, V. M. \& Colonno R. J. Substrate requirements of human rhinovirus $3 \mathrm{C}$ protease for peptide cleavage in vitro. J. Biol. Chem. 265, 9062-9065 (1990).

39. Mayer, J. P., Zhang, F. \& DiMarchi, R. D. Insulin structure and function. Biopolymers 88, 687-713 (2007)

40. Thibaudeau, K. et al. Synthesis and evaluation of insulin-human serum albumin conjugates. Bioconjugate Chem. 16, 1000-1008 (2005).

41. Disotuar, M. M., et al. Synthesis of hydrophobic insulin-based peptides using a helping-hand strategy. Org. Biomol. Chem. 17, 1703-1708 (2019).

42. Wilkinson, K. A. \& Henley, J. M. Mechanisms, regulation and consequences of protein SUMOylation. Biochem J. 428, 133-145 (2010).

\section{Acknowledgements}

This work is supported by SERB, DBT, DAE, Ramanujan Fellowship, and IISER Bhopal L.P., S.R.A., D.G.R., U.S. and M.G. are the recipients of a research fellowship from CSIR UGC, and IISER Bhopal. We thank Dr. Benjamin Rotstein (University of Ottawa, Canada) for his critical comments. We thank Dr. Manoj Kumar Bhat and Dr. Jomon Joseph of NCCS, Pune for providing the IR $\beta$ over-expressing $\mathrm{CHO}$ cells.

\section{Author contributions}

V.R. and L.P. conceived the research. L.P., S.R.A. and U.V.B. designed and performed the bioconjugation experiments. R.K.M. designed the experiments related to insulin bioactivity assay. U.S., M.G., L.P. and U.V.B. performed the biological assays. D.G.R. synthesized and characterized a set of reagents. All the authors wrote the manuscript.

\section{Additional information}

Supplementary Information accompanies this paper at https://doi.org/10.1038/s41467019-10503-7. 
Competing interests: V.R. is the founder of Plabeltech Private Limited. A patent application has been filed on this work with V.R. and L.P. as inventors (Patent application no. WO-2018104962-A1, June 14, 2018). The remaining authors declare no competing interests.

Reprints and permission information is available online at http://npg.nature.com/ reprintsandpermissions/

Journal peer review information: Nature Communications thanks Knud Jensen and other anonymous reviewer(s) for their contribution to the peer review of this work.

Publisher's note: Springer Nature remains neutral with regard to jurisdictional claims in published maps and institutional affiliations. (c) Open Access This article is licensed under a Creative Commons Attribution 4.0 International License, which permits use, sharing, adaptation, distribution and reproduction in any medium or format, as long as you give appropriate credit to the original author(s) and the source, provide a link to the Creative Commons license, and indicate if changes were made. The images or other third party material in this article are included in the article's Creative Commons license, unless indicated otherwise in a credit line to the material. If material is not included in the article's Creative Commons license and your intended use is not permitted by statutory regulation or exceeds the permitted use, you will need to obtain permission directly from the copyright holder. To view a copy of this license, visit http://creativecommons.org/ licenses/by/4.0/

(C) The Author(s) 2019 